\title{
Thorsellia anophelis gen. nov., sp. nov., a new member of the Gammaproteobacteria
}

\author{
Correspondence \\ Peter Kämpfer \\ peter.kaempfer@agrar. \\ uni-giessen.de
}

\author{
Peter Kämpfer, ${ }^{1}$ Jenny M. Lindh, ${ }^{2}$ Olle Terenius, $^{2}$ Siamak Haghdoost, ${ }^{2}$ \\ Enevold Falsen, ${ }^{3}$ Hans-Jürgen Busse ${ }^{4}$ and Ingrid Faye ${ }^{2}$ \\ ${ }^{1}$ Institut für Angewandte Mikrobiologie, Justus-Liebig-Universität Giessen, \\ IFZ-Heinrich-Buff-Ring 26-32, D-35392 Giessen, Germany \\ ${ }^{2}$ Department of Genetics, Microbiology and Toxicology, S-106 91 Stockholm University, \\ Stockholm, Sweden \\ ${ }^{3}$ CCUG, Culture Collection University of Göteborg, Göteborg, Sweden \\ ${ }^{4}$ Institut für Bakteriologie, Mykologie und Hygiene, Veterinärmedizinische Universität, Wien, \\ Austria
}

\begin{abstract}
A Gram-negative, rod-shaped organism (CCUG 49520 ${ }^{\top}$ ) was isolated from the midgut of the mosquito Anopheles arabiensis. 16S rRNA gene sequence analysis demonstrated that this isolate is unique, showing $<93 \%$ similarity to species of the families Enterobacteriaceae and Vibrionaceae. The quinone system consisted exclusively of ubiquinone Q-8; the polar lipid profile consisted of the major compounds phosphatidylethanolamine and phosphatidylglycerol, a moderate to minor amount of two unknown aminophospholipids, an unknown phospholipid and two unknown polar lipids; the polyamine pattern was characterized by the predominant compound 1,3-diaminopropane and showed some significant differences when compared with members of the Enterobacteriaceae and Vibrionaceae. On the basis of 16S rRNA gene sequence analysis in combination with chemotaxonomic data, strain CCUG $49520^{\top}$ is considered to represent a new genus and species, for which the name Thorsellia anophelis gen. nov., sp. nov. is proposed. The type strain is CCUG $49520^{\top}\left(=\right.$ CIP $\left.108754^{\top}\right)$.
\end{abstract}

During the characterization of organisms from the midgut of the mosquito Anopheles arabiensis originating from Kenya, strain $\mathrm{H} 2.1^{\mathrm{T}}$ was recovered (Lindh et al., 2005). Subcultivation was performed on nutrient agar (Oxoid) at $37^{\circ} \mathrm{C}$ for $24 \mathrm{~h}$ for up to 7 days and strain CCUG $49520^{\mathrm{T}}$ was recovered. On this agar, CCUG $49520^{\mathrm{T}}$ was able to grow at $10-37^{\circ} \mathrm{C}$, but not at 4 or $45^{\circ} \mathrm{C}$. Growth was slow in general. The organism was able to grow on nutrient agar, tryptone soy agar and R2A agar, and also weakly on MacConkey agar (all from Oxoid). Tests for growth were performed in LuriaBertani broth at $10-50{ }^{\circ} \mathrm{C}\left(5^{\circ} \mathrm{C}\right.$ intervals $)$ with shaking at 160 r.p.m. Growth occurred at $15-45^{\circ} \mathrm{C}$ with an optimum at $30^{\circ} \mathrm{C}$. The generation time at $30^{\circ} \mathrm{C}$ was $100 \mathrm{~min}$. Gramstaining was performed as described by Gerhardt et al. (1994). Preparation of bacterial DNA for G $+C$ content estimations was performed using the blood and cell culture

Published online ahead of print on 23 September 2005 as DOI 10.1099/ijs.0.63999-0.

The GenBank/EMBL/DDBJ accession number for the 16S rRNA gene sequence of strain CCUG $49520^{\top}$ is AY837748.

A two-dimensional thin-layer chromatogram of the polar lipids of strain CCUG $49520^{\top}$ is available as supplementary material in IJSEM Online.
DNA midi kit from Qiagen according to the manufacturer's instructions. $\mathrm{G}+\mathrm{C}$ content was determined by HPLC (Svoboda \& Harms-Ringdahl, 2002). Cell morphology was observed under a Zeiss light microscope at $\times 1000$, using cells that had been grown for 3 days at $37^{\circ} \mathrm{C}$ on nutrient agar; results are given under the species description below.

The 16S rRNA gene was analysed as described previously (Kämpfer et al., 2003). Analysis of the sequence data was performed by using the software package MEGA version 2.1 (Kumar et al., 2001), after multiple alignments of the data using CLUSTAL X (Thompson et al., 1997). A distance matrix method (distance options according to the Kimura twoparameter model), including clustering by neighbour-joining (Fig. 1a), and a discrete character-based maximumparsimony method (Fig. 1b) were used. In each case, bootstrap values were calculated based on 1000 replications. The 16S rRNA gene sequence of strain CCUG $49520^{\mathrm{T}}$ was a continuous stretch of $1498 \mathrm{bp}$. Sequence similarity calculations indicated that strain CCUG $49520^{\mathrm{T}}$ showed the greatest degree of similarity to Serratia rubidaea DSM $4480^{\mathrm{T}}$ (GenBank accession no. AJ233436; 92·1 \%). Lower sequence similarities $(<92 \%)$ were found with all other species of the family Enterobacteriaceae. 


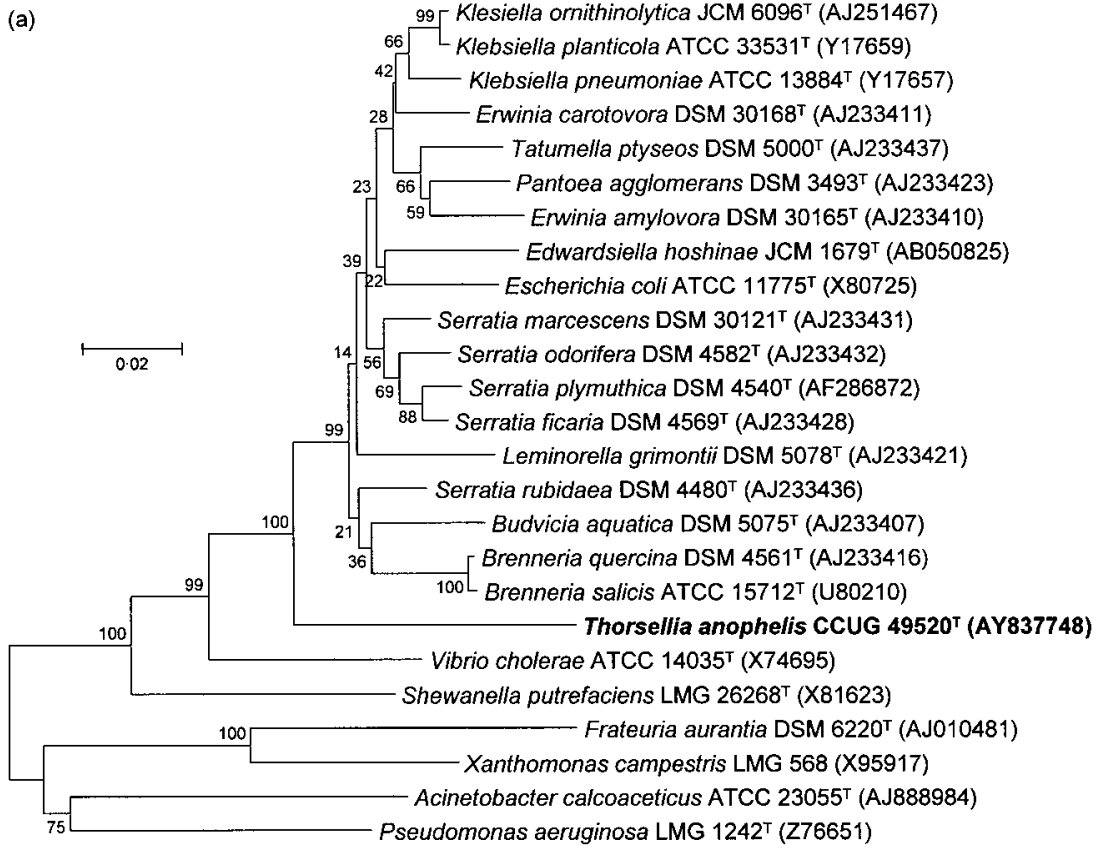

(b)

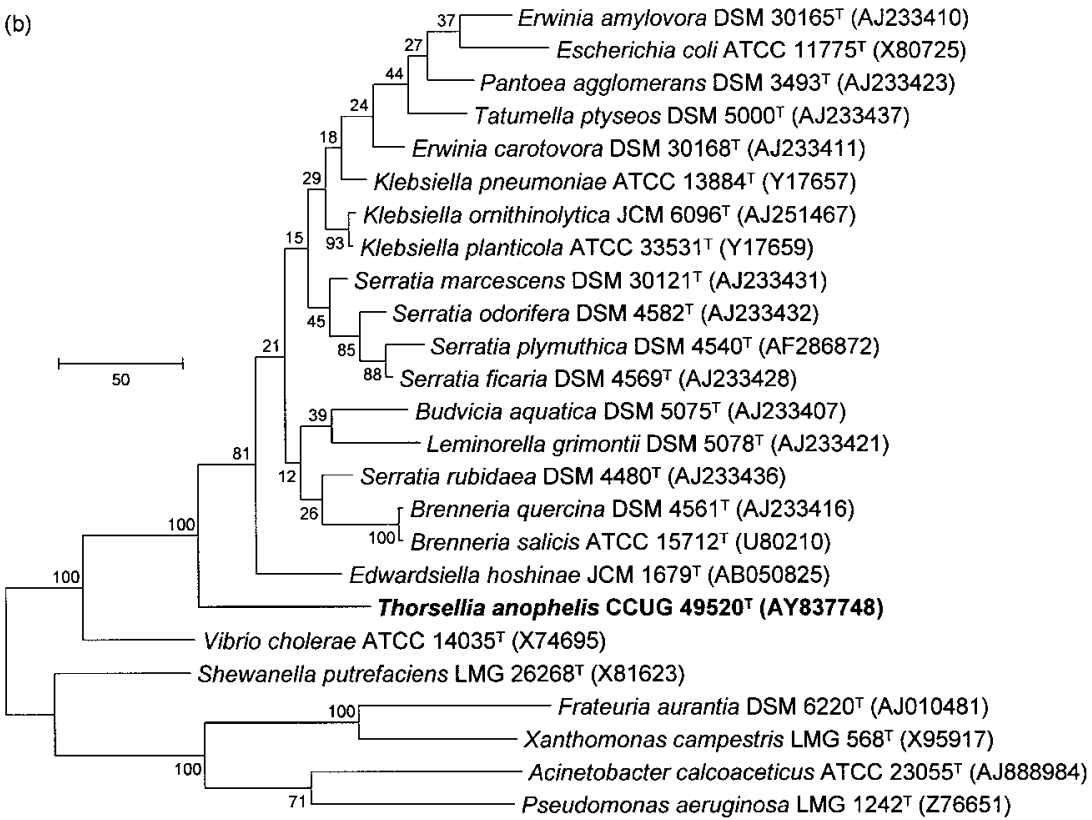

Fig. 1. Phylogenetic analysis based on $16 \mathrm{~S}$ rRNA gene sequences available from the EMBL database (accession numbers given in parentheses) constructed after multiple alignments of the data by CLUSTAL $x$ (Thompson et al., 1997). (a) Neighbour-joining tree. Distances (distance options according to the Kimura two-parameter model) were calculated and clustering with the neighbourjoining method was performed by using the software package MEGA version 2.1 (Kumar et al., 2001). Bootstrap values based on 1000 replications are listed as percentages at branch points. Bar, $2 \%$ sequence divergence. (b) Phylogenetic tree constructed under the maximum-parsimony criterion performed by using the software package MEGA with the following settings. For maximumparsimony tree search options: the heuristic search (Close-Neighbour-Interchange). For scoring changes: the MEGA standard method (in which all nucleotide changes are weighted equally). Tree length is given by the sum of minimum numbers of substitutions. Bootstrap values based on 1000 replications are listed as percentages at branch points. Bar, 50 substitutions.
Chemotaxonomic analyses were made of the respiratory quinones (Tindall, 1990; Altenburger et al., 1996), polar lipids (Tindall, 1990), fatty acids (Kämpfer \& Kroppenstedt, 1996) and polyamines (Busse \& Auling, 1988; Busse et al., 1997).

The fatty acid profile of strain CCUG $49520^{\mathrm{T}}$ (given in the species description) was similar to those of other species of the Enterobacteriaceae.

The detection of a polar lipid profile with the major compounds phosphatidylethanolamine and phosphatidylglycerol (see Supplementary Fig. S1 available in IJSEM Online) is in good agreement with characteristics of representatives of the Enterobacteriaceae and Vibrionaceae (for review see Wilkinson, 1988). However, species of the Enterobacteriaceae were reported also to contain significant amounts of diphosphatidylglycerol, while this lipid was shown to be present only in trace amounts in species of the Vibrionaceae. No diphosphatidylglycerol was detected in polar lipid extracts of strain CCUG $49520^{\mathrm{T}}$, in contrast to results for Serratia (Wilkinson, 1988). The polar lipid profile of strain CCUG $49520^{\mathrm{T}}$ is more similar to those of members of the Vibrionaceae.

Detection of the quinone system Q-8 is in agreement with the phylogenetic affiliation of CCUG $49520^{\mathrm{T}}$ because Q-8 has been reported to be present in all representatives of the 
Enterobacteriaceae and Vibrionaceae (Yokota et al., 1992). The detection of a polyamine pattern with the single major compound 1,3-diaminopropane clearly distinguishes strain CCUG $49520^{\mathrm{T}}$ from species of the Vibrionaceae, which were reported characteristically to contain sym-norspermidine (Yamamoto et al., 1983, 1991; Hamana, 1997). Among more than 70 analysed species of Enterobacteriaceae, a similar polyamine pattern has only been reported for five strains of Erwinia amylovora (Zherebilo et al., 2001) and Serratia marcescens IAM $12142^{\mathrm{T}}$ [only when grown on a highly specified cell culture medium (Hamana, 1996)]. However, the polyamine pattern of this latter strain also contained moderate amounts of putrescine and cadaverine ( $>10 \%$ of the total polyamine content). On a more common medium (nutrient broth), the same Serratia strain showed a polyamine pattern with the predominant compound cadaverine and moderate to major amounts of 1,3-diaminopropane and putrescine. All Serratia species examined by Hamana (1996) exhibited as a common feature in the polyamine pattern the presence of moderate to major amounts of cadaverine ( $>10 \%$ of the total polyamine content) and most of them also contain at least moderate amounts of putrescine. In the polyamine pattern of CCUG $49520^{\mathrm{T}}$, by contrast, cadaverine was completely lacking and putrescine could only be detected in trace amounts. Hence, the polyamine pattern alone allows differentiation of strain CCUG $49520^{\mathrm{T}}$ from the indicated relatives of the family Enterobacteriaceae, including the genus Serratia.

Results of the physiological characterization of strain CCUG $49520^{\mathrm{T}}$ are given in the species description, determined using the methods of Kämpfer (1990) and Kämpfer et al. (1991). Strain CCUG $49520^{\mathrm{T}}$ was able to produce acid from various carbohydrates, but carbon substrate utilization tests showed weak results, even after incubation for several days. On the basis of the results presented we propose that strain CCUG $49520^{\mathrm{T}}$ constitutes a member of a new genus and species, for which the name Thorsellia anophelis gen. nov., sp. nov. is proposed.

\section{Description of Thorsellia gen. nov.}

Thorsellia (Thor.sel'li.a. N.L. fem. n. Thorsellia named in honour of Walborg Thorsell, a pioneer on mosquito repellent research in Sweden).

Cells are Gram-negative, facultatively anaerobic, motile and rod-shaped. Growth on all tested media is slow. Growth occurs after $48 \mathrm{~h}$ incubation on tryptone soy agar and nutrient agar at $37^{\circ} \mathrm{C}$; good growth also occurs at $30^{\circ} \mathrm{C}$. Growth occurs in Luria-Bertani broth at $15-45^{\circ} \mathrm{C}$ with an optimum at $30^{\circ} \mathrm{C}$, at which the generation time is $100 \mathrm{~min}$. 1,3-Diaminopropane is the characteristic compound in the polyamine pattern, ubiquinone Q-8 is the single quinone and in the polar lipid profile phosphatidylethanolamine and phosphatidylglycerol are predominant. The major fatty acids are $\mathrm{C}_{16: 0}, \mathrm{C}_{18: 1} \omega 7 c$ and $\mathrm{C}_{14: 0}$. The DNA G+C content is $46 \mathrm{~mol} \%$. The type species is Thorsellia anophelis.

\section{Description of Thorsellia anophelis sp. nov.}

Thorsellia anophelis (a.no' phe.lis. N.L. gen. n. anophelis from a mosquito of the genus Anopheles).

Exhibits the following properties in addition to those given in the genus description. Slow growth occurs after $24 \mathrm{~h}$ incubation on tryptone soy agar and nutrient agar at $37^{\circ} \mathrm{C}$. The fatty acid profile comprises $\mathrm{C}_{16: 0}(32.9 \%), \mathrm{C}_{18: 1} \omega 7 c$ $(35.9 \%), C_{14: 0}(12 \cdot 2 \%), C_{18: 0}(1 \cdot 0 \%), C_{12: 0} 3-O H$ $(0 \cdot 8 \%)$, summed feature $2\left(\mathrm{C}_{14: 0} 3-\mathrm{OH} /\right.$ iso I $\mathrm{C}_{16: 1}$, $5 \cdot 4 \%)$ and summed feature $3\left(\mathrm{C}_{16: 1} \omega 7 \mathrm{c} /\right.$ iso- $\mathrm{C}_{15: 0} 2-\mathrm{OH}$, $8.0 \%)$. The polar lipid profile contains moderate to minor amounts of two unknown aminophospholipids, an unknown phospholipid and two unknown polar lipids; when the organism is grown under strictly aerobic conditions, the quinone system consists exclusively of ubiquinone Q-8; the polyamine pattern consists of the predominant compound 1,3-diaminopropane $\left[94 \cdot 1 \mu \mathrm{mol}(\mathrm{g} \text { dry weight })^{-1}\right]$, spermidine $\left.[1.5 \mu \mathrm{mol} \text { (g dry weight })^{-1}\right]$ and traces $[<1 \cdot 0 \mu \mathrm{mol}(\mathrm{g}$ dry weight $\left.)^{-1}\right]$ of putrescine and sym-homospermidine. Aesculin is hydrolysed. Positive for acid production from glucose (O/F positive after $48 \mathrm{~h}$ incubation), lactose, sucrose, D-mannitol, dulcitol, salicin, adonitol, inositol, rhamnose, maltose, trehalose, cellobiose, D-arabitol and D-mannose. No acid is produced from sorbitol, L-arabinose, raffinose, D-xylose, methyl D-glucoside, erythritol or melibiose. The following carbon sources are utilized (only after prolonged incubation, 7 days): $p$-arbutin, D-gluconate, D-glucose, sucrose, D-trehalose, D-xylose, adonitol, myo-inositol, maltitol, D-mannitol, acetate, propionate, cis-aconitate, trans-aconitate, adipate, fumarate, DL-3-hydroxybutyrate, DL-lactate, L-malate, mesaconate, pyruvate, L-alanine and L-leucine. The following substrates are not utilized as carbon sources: $N$-acetyl-D-galactosamine, $N$-acetyl-D-glucosamine, salicin, D-sorbitol, putrescine, 4-aminobutyrate, azelate, citrate, glutarate, itaconate, oxoglutarate, suberate, $\beta$-alanine, L-aspartate, L-histidine, L-ornithine, L-phenylalanine, L-proline, L-serine, L-tryptophan, 3-hydroxybenzoate, 4-hydroxybenzoate and phenylacetate. Negative for hydrolysis of $p$-nitrophenyl (pNP) $\beta$-D-glucopyranoside, $o$-nitrophenyl (oNP) $\beta$-D-galactopyranoside, pNP $\beta$-D-glucuronide, $\mathrm{pNP}$ $\alpha$-D-glucopyranoside, pNP $\beta$-D-xylopyranoside, bis-pNP phosphate, pNP phenylphosphonate, pNP phosphorylcholine, 2-deoxythymidine-5'-pNP phosphate, L-alanine $p$-nitroanilide (pNA), L-glutamate- $\gamma$-3-carboxy pNA and L-proline pNA.

The type strain is CCUG $49520^{\mathrm{T}}\left(=\operatorname{CIP} 108754^{\mathrm{T}}\right)$, isolated from the midgut contents of the mosquito Anopheles arabiensis.

\section{References}

Altenburger, P., Kämpfer, P., Makristathis, A., Lubitz, W. \& Busse, H.-J. (1996). Classification of bacteria isolated from a medieval wall painting. J Biotechnol 47, 39-52.

Busse, H.-J. \& Auling, G. (1988). Polyamine pattern as a chemotaxonomic marker within the Proteobacteria. Syst Appl Microbiol 11, 1-8. 
Busse, H.-J., Bunka, S., Hensel, A. \& Lubitz, W. (1997). Discrimination of members of the family Pasteurellaceae based on polyamine patterns. Int J Syst Bacteriol 47, 698-708.

Gerhardt, P., Murray, R. G. E., Wood, W. A. \& Krieg, N. R. (editors) (1994). Methods for General and Molecular Bacteriology. Washington, DC: American Society for Microbiology.

Hamana, K. (1996). Distribution of diaminopropane and acetylspermidine in Enterobacteriaceae. Can J Microbiol 42, 107-114.

Hamana, K. (1997). Polyamine distribution patterns within the families Aeromonadaceae, Vibrionaceae, Pasteurellaceae, and Halomonadaceae, and related genera of the gamma subclass of the Proteobacteria. J Gen Appl Microbiol 43, 49-59.

Kämpfer, P. (1990). Evaluation of the Titertek-Enterobac-Automated System (TTE-AS) for identification of members of the family Enterobacteriaceae. Zentralbl Bakteriol 273, 164-172.

Kämpfer, P. \& Kroppenstedt, R. M. (1996). Numerical analysis of fatty acid patterns of coryneform bacteria and related taxa. Can J Microbiol 42, 989-1005.

Kämpfer, P., Steiof, M. \& Dott, W. (1991). Microbiological characterisation of a fuel-oil contaminated site including numerical identification of heterotrophic water and soil bacteria. Microb Ecol 21, 227-251.

Kämpfer, P., Dreyer, U., Neef, A., Dott, W. \& Busse, H.-J. (2003). Chryseobacterium defluvii sp. nov., isolated from wastewater. Int J Syst Evol Microbiol 53, 93-97.

Kumar, S., Tamura, K., Jakobsen, I.-B. \& Nei, M. (2001). MEGA2: molecular evolutionary genetics analysis software. Bioinformatics 17, 1244-1245.

Lindh, J. M., Terenius, O. \& Faye, I. (2005). 16S rRNA gene-based identification of midgut bacteria from field-caught Anopheles gambiae sensu lato and $A$. funestus mosquitoes reveals new species related to known insect symbionts. Appl Environ Microbiol 71, 7217-7223.

Svoboda, P. \& Harms-Ringdahl, M. (2002). Kinetics of phosphatemediated oxidation of ferrous iron and formation of 8-oxo- $2^{\prime}$ deoxyguanosine in solutions of free $2^{\prime}$-deoxyguanosine and calf thymus DNA. Biochim Biophys Acta 1571, 45-54.

Thompson, J. D., Gibson, T. J., Plewniak, F., Jeanmougin, F. \& Higgins, D. G. (1997). The CLUSTAL_X Windows interface: flexible strategies for multiple sequence alignment aided by quality analysis tools. Nucleic Acids Res 25, 4876-4882.

Tindall, B. J. (1990). Lipid composition of Halobacterium lacusprofundi. FEMS Microbiol Lett 66, 199-202.

Wilkinson, S. G. (1988). Gram-negative bacteria. In Microbial Lipids, vol. 1, pp. 299-488. Edited by C. Ratledge \& S. G. Wilkinson. New York: Academic Press.

Yamamoto, S., Shinoda, S., Kawaguchi, M., Wakamatsu, K. \& Makita, M. (1983). Polyamine distribution in Vibrionaceae: norspermidine as a general constituent of Vibrio species. Can J Microbiol 29, 724-728.

Yamamoto, S., Chowdhury, M. A. R., Kuroda, M., Nakano, T., Koumoto, Y. \& Shinoda, S. (1991). Further study on polyamine compositions in Vibrionaceae. Can J Microbiol 37, 148-153.

Yokota, A., Akagawa-Matsushita, M., Hiraishi, A., Katayama, Y., Urakami, T. \& Yamasato, K. (1992). Distribution of quinone systems in microorganisms: Gram-negative eubacteria. Bull JFCC 8, 136-171.

Zherebilo, O., Kucheryava, N., Gvozdyak, R. I., Ziegler, D., Scheibner, M. \& Auling, G. (2001). Diversity of polyamine patterns in soft rot pathogens and other plant-associated members of the Enterobacteriaceae. Syst Appl Microbiol 24, 54-62. 